\title{
Redefining Roles: Female Scholars' Reflections and Recommendations for Coping During the COVID-19 Pandemic
}

\author{
Kelly J. Brochu \\ Regis College Department of Education \\ kelly.brochu@regiscollege.edu \\ Amanda J. Jensen \\ Regis College Department of Education \\ ajen891@regiscollege.edu \\ Regina M. M. Robinson \\ Regis College Department of Education \\ rrob589@regiscollege.edu
}

\author{
Trina R. Bryant \\ Regis College Department of Education \\ tbry303@regiscollege.edu \\ Danielle R. Desjardins \\ Regis College Department of Education \\ ddes267@regiscollege.edu \\ Lauren G. Bent \\ Regis College Department of Education \\ lauren.bent@regiscollege.edu
}

\begin{abstract}
The objective of this article is to amplify the stories of female doctoral students and their passage through role conflicting periods of uncertainty and trauma. Specifically, this article highlights how the COVID-19 pandemic and racial unrest in the U.S. have impacted women pursuing doctorates in education. In addition to sharing personal reflections and experiences, the authors have outlined resources and recommendations for those who support doctoral students. Through the diverse perspectives of five students and one faculty member in the EdD in Higher Education Leadership program at Regis College, this article explores the lived experiences of second-year doctoral students during an incredible period of uncertainty. Douglas T. Hall's model of coping serves to frame content around the many conflicting roles these students have been navigating and found to be exacerbated during the year 2020. This article seeks to empower leaders to re-envision approaches to support doctoral students through future crises and periods of uncertainty.
\end{abstract}

\section{KEYWORDS}

EdD student, doctoral student, COVID-19, role conflict, female scholar, scholar practitioner, coping strategies.

The COVID-19 pandemic posed significant challenges to EdD students in a Higher Education Leadership program, as jobs, doctoral work, and home-life collide, and every role and responsibility demanded more time. As second-year doctoral students, we have no longer been able to employ the strategies that initially helped us manage our multiple roles while persisting through our EdD program. It is under these circumstances of conflicting roles that we have examined the role conflict of women in EdD programs during the pandemic through a self-narrative. Through these narratives, we explore the experiences of six women, diverse in age, race, religion, marital status, parental responsibilities, economic status, and occupations within higher education. Five of us are second-year students in an EdD program, and one is our faculty member and administrator for the EdD program.

While understanding the biases we bring to this discussion as scholarly practitioners, we are aiming to raise awareness and recognize the growth that takes place in fostering meaningful relationships, particularly in the context of role conflict management.
Additionally, we strive to increase the scarcity of research that exists that explores coping mechanisms and support structures designed for scholarly practitioners in EdD programs.

\section{PROBLEM OF PRACTICE}

In addition to the overwhelming stress and uncertainty experienced during the COVID-19 pandemic, women also experienced an increase in the gender-specific pressures imposed on them. These pressures came in the form of higher performance expectations despite decreased support or resources, harsher criticism for mistakes made, and unfair penalties for being mothers or caregivers (McKinsey \& Company \& LEAN IN, 2020). For women in higher education, the impact of these biases often creates challenges that include a struggle to engage in scholarly work, establish a healthy work-life-balance, and prioritize career advancement through refuting the additional service work that

New articles in this journal are licensed under a Creative Commons Attribution 4.0 United States License. 
hinders leadership and scholarly productivity. This can lead to women remaining in lower levels of leadership than their male counterparts (McKinsey \& Company \& LEAN IN, 2020).

Since mid-March, the pandemic has added an additional layer of stress to everyday work- life balance; simultaneously, racial unrest throughout the U.S. intensified due to the murders of unarmed Black Americans. As our society was transitioning to stay at home orders, a 26-year-old Black woman named Breonna Taylor was shot and killed by police in her Louisville home. In the weeks to follow, video footage surfaced that showcased the murder of 25-year-old Ahmaud Arbery, a Black man shot and killed by White men while jogging in his Georgia neighborhood. This dramatic footage sent palpable shockwaves across the country and left people stuck at home, watching the news, and grappling with the realities of racism on American soil. Several weeks later, raw video footage emerged of the murder of George Floyd, a Black man in Minnesota, who was killed in broad daylight while apprehended by local police. This footage seemed to be the final spark necessary to ignite the fire of outrage across the United States. Smithsonian Secretary Lonnie G. Bunch wrote that the killing of Floyd has "forced the country to confront the reality that, despite gains made in the past 50 years, we are still a nation driven by inequality and racial division" (Solly, 2020, para. 1). Shortly after these events, protests broke out across the globe with protestors demanding justice for the lives lost.

Compounded with the continued trauma of the COVID-19 pandemic, these racial protests and sincere fear of personal safety upended our sense of normalcy, required us to develop new ways to cope, and forced us to reevaluate the roles we held in our lives.

\section{THEORETICAL FRAMEWORK: COPING AS A WOMAN}

Robert L. Kahn's concept of inter-role conflict encompasses one's understanding of how the pressures from identified roles, such as identifying as a scholarly practitioner, doctoral student, and as an employee for an institution of higher education, may present conflicting obligations between one another (Kahn et al., 1964). Scholarly practitioners, specifically in higher education, hold roles with the utmost responsibility; to approach problems in practice through reputable research in tandem with fostering collaboration with institution stakeholders (CPED, 2020). Furthering Kahn et al.'s (1964) work, Douglas T. Hall (1972) developed a model of coping which suggests that women often take on multiple roles concurrently, which presents inter-role conflict due to competing demands such as being a wife, mother, caregiver, and employee. These experiences are different from their male counterparts, as women maintain these responsibilities while remaining in lower levels of leadership (McKinsey \& Company \& LEAN IN, 2020). This theory also encompassed three levels of coping as applied to college-educated women: "structural role definition," "personal role redefinition," and "reactive role behavior."

The "reactive role behavior" coping style describes the attempt to satisfy all directives from role-senders by enhancing performance in occupied roles (Hall, 1972). Hall's (1972) findings demonstrated that college-educated women often embody this coping type by working as hard as possible, enhancing planning and organization skills without grasping a firm, long-term strategy.

Based on our own experiences, we employed the "reactive role behavior" coping style in the early stages of the pandemic, through self-identified passion, resilience, and dedication to the roles occupied; yet the confidence to maintain such a superior quality of service is not necessarily as significant. Our individual narratives highlight feeling the need to "do it all," which included daily job performance, transitioning children to remote learning, and completing an increased amount of household tasks, all while accomplishing EdD coursework. Often this "do it all" mentality meant compromising self-care coping strategies and putting others before ourselves.

The second type of Hall's coping, "personal role redefinition," is deemed a defense mechanism (1972). This occurs when individuals change the personal interpretation of the demands received from role-senders (Hall, 1972). In our experiences, role senders included our supervisors, direct reports, students, spouses, partners, children, and EdD faculty members. Hall's (1972) findings reveal that collegeeducated women exhibit this through establishing priorities for role responsibilities. This manifests as prioritizing one role over another; causing one to overlook or eliminate required role tasks from the role sender and divert away from roles geared towards self-focused interest (Hall, 1972).

The use of this coping style intensified as we continued to be challenged with managing the escalating responsibilities attributed to each role we held. Since the beginning of the pandemic, students were forced to cope with losses, on all fronts, in ways that had not been explored before. We filled voids left by the loss of loved ones due to COVID-19 and the shift from a sense of normalcy with coursework for the EdD program and increased connections with classmates. Funerals were postponed, and significant milestones were left uncelebrated. We discovered the necessity to re-evaluate what needed to be done to meet the immediate needs of the moment sometimes facing conflicts between personal and professional needs.

Hall's (1972) final coping strategy, "structural role definition," can be achieved through altering the structured expectations imposed by others, such as the role-senders (Hall, 1972). At the onset of the summer term, nearly one year after we began our EdD program, we exhibited coping strategies that embodied "structural role redefinition." During this period, our collective narratives revealed a greater level of self-confidence that fueled the need to reevaluate our roles with role-senders as the pandemic continued. In doing so, we shared how we initiated conversations pertaining to ways in which responsibilities could be adapted to complement work objectives as well as personal trajectories.

In the workplace, additional tasks such as committee membership and appointments to various task forces, are assumed as part of the commitment to community or contractual obligations; women are frequently asked to take on more commitments than men (Babcock et al., 2017). Through these extraneous and unexpected service obligations, women find themselves in a potential dilemma of having to choose between serving as the female representation on multiple committees or following personal pursuits that lead to promotions such as research or publications (Babcock et al., 2017). Research also indicates that service, such as committee work, is less valued than scholarship in promotional considerations (Babcock et al., 2017). This disparity in task distribution furthers the difficulty of women ascending in leadership faculty ranks (Babcock et al., 2017; Guarino \& Borden, 2017; Mitchell \& Hesli, 2013).

While this disparity is experienced differently by each of us, we have all benefited from the support of peers and faculty in our EdD 
program in further developing our confidence to continue to act as change agents in our respective roles both in and out of our EdD program. It is in these challenges that we are demonstrating Hall's "structural role definition" as it relates to gender bias in higher education leadership.

\section{Coping as a Black Woman}

Role conflict created a different set of needs surrounding "structural role definition" for Black women as they faced the punctuated equilibrium caused by COVID-19 and racial unrest throughout the country. These detriments that turned people's lives and workplaces upside down exposed the local and global community to the pre-existing health and educational disparities faced by communities of color. The three groups facing these distinct challenges are mothers, senior-level women, and Black women (McKinsey \& Company \& LEAN IN, 2020). Walkington (2017) argued that Black women faculty often feel "relegated to race-specific positions considered not as academic, have limited access to mentors who can understand their unique experiences and insights, and help move them toward research grants, full time faculty appointments and achieving tenure" (p. 55). This reality often means that Black faculty and other faculty of color experience what Writer and Watson (2019) referred to as "service stress" (p. 38).

As mentioned previously, Babcock et al. (2017) argued that women are asked more often than their male counterparts to participate in such service, which can benefit the community, but can also hinder scholarly work that is more likely to be celebrated and lead to career advancement. This dynamic can cause service stress, where female faculty and faculty of color are asked and, in some cases, feel pressured, to volunteer for additional service activities beyond their responsibilities (Babcock et al. 2017). Service stress can impact the well-being of faculty and lead to retention issues. For example, Walkington (2017) suggested that the inability of higher education institutions to recruit and retain faculty of color is in part due to this dynamic. In an attempt to create more inclusive environments and to address diversity deficits, educators of color are frequently asked and expected to engage in service activities, such as mentoring all of the new faculty, staff, and students from marginalized groups, helping to facilitate dialogues, and professional development on race, equity, and diversity; undertakings that are in addition to their required work, and are not often rewarded or highlighted in the same way as other responsibilities.

Some faculty of color who leave an institution report that they felt overwhelmed and stressed by the number of committees they were expected to participate in and the additional responsibilities that they were asked to take on. As a person of color, serving as this representation on multiple committees can be time-consuming and both physically and emotionally taxing. These experiences can also compromise mental health as well as scholarship work (Walkington, 2017; Writer \& Watson, 2019). In comparison to women of other races and ethnic backgrounds, Black women face more systemic barriers, receive less support from managers, and experience more acute discrimination (McKinsey \& Company \& LEAN IN, 2020). This adds to the need to address role senders about "structural role definition" and the specific needs of employees of color during this time.

\section{Our Experiences*}

*In some cases, pseudonyms have been used in this section.

\section{Dianna}

The experience of enduring the Pandemic while being an EdD student, a spouse, and a mom of a pre-teen has been distressing, disjointed, upended, and surreal. COVID-19 disrupted everything from faith relations and home-life to work and school obligations. While most Americans felt the brunt of the Pandemic's force in midMarch, I was impacted in January when exchange students from China residing with my family were first alerted to the Pandemic hitting home. The rhythm and efficiency used to balance my many roles was no longer possible.

In normal times, I found faith as a grounding force whose presence was greatly missed when worshiping with others was prohibited and religious services moved online. Without this, the rapidly increasing demands of being a mom, a wife, a doctoral student, a professor, and a woman, all seemed to demand more time than what was available. I was forced to reprioritize and reimagine this new lifestyle and manage the new challenges and emotions that came with it. There is no going back...but looking ahead trying to imagine a brighter future that's hard, especially when social gatherings still carry large risks, shortages of daily necessities demand a whole new way of providing what families need, and children are doing hybrid learning.

\section{Alexandria}

As the only student who does not reside in Massachusetts, I faced a challenging experience in a state that was impacted incredibly hard at the onset of the pandemic. Feelings of terror, anxiety, uncertainty, and hopelessness posed struggles for me to regulate emotions and balance expectations. After losing a parent a year prior, the deadly threat of the Pandemic was extremely real to my close-knit family, and the horror of possibly spreading the disease was consistently overwhelming. Furthermore, at what seemed to be the height of the Pandemic, racial tensions in the country were also at an incredible high, as lives of Black and Brown people were taken at the hands of law enforcement; these events derailed everything. My emotions were flowing, I missed class assignments, and a I had a genuine fear for what was going to happen next; it was all-consuming. There were days when I would just sit on my couch and cry as I read the news. "How could this be real?" is what I would ask myself. I love my students like family, but I was terrified to ask them how they were doing because I knew, emotionally and mentally, I could not handle their response. The guilt of not stepping up for them still lingers with me.

At the lowest point, I sought professional support to manage depression and anxiety and found relief in the practice of yoga. Additionally, receiving unwavering support from classmates in the EdD program was the best thing to come out of this awful experience.

\section{Barbara}

In the midst of grieving the death of a family member, nurturing the morale of student-facing professionals that I supervise, and navigating my own sense of patience and adaptability to unexpected changes, I found an anchor through my doctoral education and family. They truly served as a stable reminder of why I am 
passionate and committed to continuing my heart-felt service to students and staff in higher education.

I faced challenges from the Pandemic from all angles, and would define my experience as grieving, humbling, eye-opening, reflective, and validating. After losing a cherished loved one to COVID-19, I developed a deeper appreciation for those people closest and for the connections made with others. Finding joy in more quality time and careful cohesion with a spouse brought me a profound sense of gratitude despite longing for other social connections outside of Zoom.

My experience in the workplace also brought along its own challenges. Ensuring the safety and well-being of supervised student staff, managing the growing expectations, and the mounting uncertainty surrounding what was happening next, and struggling to balance it all while still being a supportive leader has been taxing. I found a saving grace through the reprieve in schoolwork and connecting with classmates. These bonds have given me a muchneeded anchor, something to look forward to, and something to count on.

\section{Michelle}

This story encapsulates the experience I have had as a Black woman, mom, wife, Dean of Student Affairs, and EdD student during the Pandemic. Closing my work laptop, I sighed deeply. It's finally Friday evening and I was exhausted as I tried to navigate the new normal of working from home while supporting virtual learning for my four children, aged 14, 12, 10, and 7. As a family, our kids looked forward to Friday dance parties and movie/pizza night, while I looked forward to no cooking prep, little cleaning, and some schoolwork for my EdD program.

But this Friday in May was different. Earlier in the week, the footage of the murder of Ahmaud Arbery, a young Black man who was shot and killed by two white men while jogging in his Georgia neighborhood, was made public. The entire week was filled with heart-wrenching news reports and as a mother of two Black boys and a wife to a strong Black man, this news felt too burdensome for my heart to bear. Friday evening, my husband and daughter wanted to jog to join the movement to \#runwithahmaud while I picked up dinner, but I didn't want them to go, fearing for their safety in light of the week's events. Feeling anxious, I later drove around looking for their route before picking up the pizza, but I couldn't find them. The stressors of this season of life were overwhelming as my heart raced in desperation to ensure their safety. Thankfully, they made it home before me and I hugged them closer that night as I then had to switch emotional gears from fear to focus as there was schoolwork that still needed to get done.

\section{Ida}

I often felt frustration, fear, and fatigue. The impact of COVID19 hit home during the spring semester as my family members and I all contracted the Virus. At a time when things were already challenging with managing schoolwork and employment related obligations, I became responsible for taking care of ill family members, who were disproportionately impacted by the Virus. As one of two Black leaders on my campus, I was drawn in many directions and faced increasing demands and pressures to provide support to grieving students, a voice to the Black campus community, and a resource for those looking to learn more about how to help. Exhaustion, both mentally and physically, set in. This exhaustion was only exacerbated when I contracted COVID-19.

While battling COVID-19, I was also enduring the nationwide racial violence and the barrage of media coverage that came with it. The daily headlines broadcasting that another Black life was tragically ended too early and the public outcries for justice for the victims began to take a toll on me. As a higher education professional, the deaths of George Floyd, Ahmaud Arbery, and Breonna Taylor felt different. After a meeting with students, it was a struggle to listen to students who were confused, angry and scared. One international student from Uganda said that he was so scared to walk down the streets of Boston and Quincy that he could not leave his host families home for months. He said he did not want to stay in the United States. I honestly, did not know how to respond. How could I tell him that as an American citizen I am scared and angry too?

In experiencing all of this, I found support from classmates, advisors, the practice of mindfulness, and my faith. Also, saying, "no" helped me establish and strengthen boundaries and ensure that I was able to focus on what was important and not be stretched too thin. These changes afforded me more free time to rest, relax, and heal.

\section{Lauren}

As a faculty member in an EdD program, mother of two children (ages 6 and 8) and wife, the pandemic illuminated my on-going approach to manage multiple roles. Prior to the pandemic, I had established a village to help me care for my children, and I had set figurative and spatial boundaries in order to raise children and fulfill job responsibilities. However, when the pandemic hit, each of my roles required more work and deeper work, and I could no longer employ the strategies I had previously used in order to fulfill my roles as a mother, wife, and associate professor. Boundaries collapsed when I was working from home while simultaneously supporting two young children with distance learning and grieving the loss of a family member. In reflecting on my own experience, I recognize that, like so many of us, I was crisis teaching and crisis parenting without practicing much self-care. Since the onset of the pandemic, I have practiced resetting expectations and priorities, becoming more adaptable, and providing a space for myself, my family, and my students to sit with emotions.

My students had similar experiences; they have assumed more pressure in their jobs and cared for family members, and facilitated distance learning for their children, all while pursuing their EdD. They, too, experienced loss, grief, uncertainty, fear, anxiety, and as their professor, I constantly thought about them and the turmoil they were experiencing as a result of the pandemic and racial justice movement. Among our EdD community, there has been a deep sense of vulnerability and authenticity and teaching these students has brought a sense of solace and connection for me during a time of physical distancing.

\section{COPING AMIDST ROLE CONFLICT}

As we continued to cope during this unprecedented time, we have identified and employed strategies which have enabled us to persist through our doctoral work while fulfilling other responsibilities. Specifically, there are four coping strategies that we used in order to adapt our approaches as female scholarly practitioners during the 
pandemic and racial protests. These strategies lead to recommendations for future scholarly practitioners who find themselves experiencing role conflict overload and for individuals and organizations who support other scholarly practitioners.

One of the strategies was self-care in order to recharge. Instead of visiting the local gym or recreation facility, we walked, rode bikes, or ran in our neighborhoods, often with our families. This also allowed us to escape the confinement of our homes and reimagine quality time with loved ones. As a whole, we lost our sense of self-care, neglecting ourselves while establishing a new routine for family members and putting their well-being far before our own. Racial fears added concerns for Black families as neighborhood outings brought what "Michelle" described as a "retraumatization of Ahmaud Arbery's murder and the fear this could happen to my own family." During this time, some of us also sought professional help in order to manage our mental health.

Another strategy was stealing away in solitude. With constant demands and continual distractions from the news, quiet space for personal recharging became an emotional necessity of soul care. For some of us, this included religious and spiritual connections, which provided more reflective spiritual support. Another source of solitude became unplugging from technology. The constant updates were depressing and anxiety inducing. Moments of solitude have become a permanent addition to the new-normal providing spiritual connectedness and fueling a deeper purpose for the work we do.

Seeking out peer support within our EdD cohort was another key strategy for coping. Amongst trusted faculty and cohort members, we discussed our shared experiences in classes, study sessions, and individual connections. As the new-normal began to impact summer plans, student-mothers reached out to one another and exchanged ideas for supporting our children's summer structure and virtual connections. The shared knowledge that students brought to our fellow classmates created a powerful bond to support the many sub-identities that, at times, compete for its share of a women's total identity (Hall, 1972). Having a diverse cohort gave us the connectedness we needed to persist; an invaluable resource that we will continue to rely upon in the future.

The final strategy we uncovered was satisfying doctoral program expectations with a shared commitment to persist with the end goal in mind. Throughout our journey as doctoral students, we face the daunting tasks of research and meeting weekly assignment deadlines that require consistent reminders of the value of individual efforts. With each assignment, classmate check-in, and cohort discussion board, the sense of progress within the semester took us one step closer to our shared goal of persisting together. Through role bargaining and repositioning of responsibilities, such as asking faculty for assignment extensions and shifting to a greater sense of mutual support, we began to reimagine the new-normal of academic persistence.

The dynamic intersectionality of our roles is key to our ability to support and accentuate the coping strategies of one another in order to academically persist through our scholarly pursuit of an EdD. The layers of overlapping intersectionality also allow us to experience each other in an authentic manner that enriches each of us both personally and professionally and helps us develop greater confidence as emerging leaders in higher education.

\section{RECOMMENDATIONS FOR PRACTICE}

Based on the coping strategies that we implemented throughout the COVID-19 pandemic, we have identified key recommendations for practice. These may be beneficial for EdD programs, EdD students, and professionals who supervise EdD students in the workplace.

\section{EdD Program}

\section{Schedule Time to Process Implications of Crises.}

One of the most prominent means of coping that we have drawn from our experiences was the benefit of having scheduled time within our EdD classes to process and discuss the pandemic and its implications. Simply having 10 minutes to share obstacles with other students cultivated a stronger connection within the Cohort while also designing an approachable space for shared strategies. Students found offering space parallels between experience and the context of their courses, such as how organizational leadership applies to decision-making and communication regarding COVID-19 within higher education communities.

\section{Continue to Foster a Sense of Community.}

Like many CPED-influenced programs, the sense of community in our EdD program among each student cohort as well as between students and faculty is strong and significant. As many of us have felt isolated during the pandemic, we appreciate the initiatives leaders in our program took to ensure that students and faculty have felt interconnected. For example, our program director sent handwritten greeting cards with a customized face mask to all cohorts. In addition, students and faculty frequently came together on Zoom calls for academic meetings as well as social events, including a toast at the end of the semester. These small gestures made us feel like we had not been forgotten; we felt like we mattered. Therefore, we recommend that EdD programs find ways to authentically build connections; this includes student-student, faculty-faculty, and faculty-student.

\section{Welcome Student and Faculty Feedback and Recommendations.}

According to McMillan and Chavis (1986), one of the four core elements of cultivating a sense of community is influence. People feel more connected to the community and invested in a shared mission when they are empowered to influence outcomes; this is particularly relevant during times of uncertainly such as the COVID19 era. As such, we recommend that EdD programs continue or adopt a culture of soliciting and incorporating feedback and recommendations from students and faculty. For students, specific examples include a survey tool to determine students' level of comfort regarding returning to campus, a course mid-semester survey tool as a temperature check, inquiring about access to synchronous online courses, and administering focus groups using Zoom videoconference. For faculty, program directors should engage faculty in the EdD program with decision-making; this can be done through formal meetings, email or text messages. 


\section{Develop an Education around Racial Identity and Systemic Disparity.}

Our narratives highlight the importance of focusing on the implications of crises on individuals of color, specifically Black individuals in the United States. Ensuring that program faculty and directors, as well as their students, receive ongoing and missiondriven education regarding the institutional disparities that are prevalent in trauma-inducing incidents is vital to the equitable support of doctoral students. Dr. Conway Campbell, professor in Regis' EdD program, shared his intentional teaching strategy, "I have introduced more sustained ways for dialogue in the classroom on race, where students can share their experiences with their fellow classmates through structured activities, modeling honest respectful communication, and stress that there are no experts just allies engaged in social action" (C. Campbell, personal communication, October 9, 2020). In order to embrace this practice, it is crucial to acknowledge and condemn what is happening and to articulate and demonstrate a commitment to advocate for Black doctoral students.

\section{Understand and Validate Students' Needs to Redefine Roles and Priorities.}

Faculty exuding empathy and validation for students' needs to redefine roles was highlighted as an asset to coping through COVID19. Finding areas of the curriculum to amend in response to students' hardship, while maintaining rigor and desired outcomes for the course, was crucial to our feeling supported while still being held to a high standard. Deadline extensions and refining assignments to have a more practical and scholarly application are strategies that demonstrate this recommendation. We also emphasize the need for EdD programs to identify opportunities for students to achieve significant milestones in scholarship during the pandemic.

\section{EdD Students}

\section{Know Thyself.}

Female students who are juggling multiple roles need to activate their self-awareness and self- actualization skills in order to attain realistic necessary role adjustments. The pandemic has intensified challenges that women faced. Now, the supports that have been traditionally implemented by women to combat the influx of responsibilities_-including school and childcare-have been upended. Meanwhile, Black women already faced more barriers to advancement than most other employees (McKinsey \& Company \& LEAN IN, 2020). It is important to propose ways to reframe the roles that one occupies that allows the desired outcomes of roles to be met, while also acknowledging the need to nourish other responsibilities that need to be managed. A theme of self-care from the narratives included the concept of gratitude alongside an appreciation for the privilege of health that one possessed during the pandemic. Although at times difficult to grasp, it is imperative to focus on the purpose in one's life, whether that be the people or the vocation that keep them moving forward.

\section{Know Thy Goals.}

Steven Covey (1989) encouraged individuals to "begin with the end in mind" in Seven Habits for Highly Effective People. Covey (1989) posited, "people are working harder than ever, but because they lack clarity and vision, they aren't getting very far. They, in essence, are pushing a rope with all of their might" (para 3 ). If earning a doctorate degree is a chief goal, then set the necessary goals for the number of years in the program. If professional advancement is a desired goal, then map out the number of promotions, projects, or tasks required to achieve the goals. Setting goals provides consistency and clarity when chaos and setbacks undoubtedly surface.

\section{Know Thy Network.}

EdD students should consider, "Who is in my network?" and stay connected with personal and professional networks. Women need connections, and oftentimes, staying connected with a network is a form of self-care. As noted in earlier vignettes, caring communities provide support, reinforce goals, and can help navigate personal well-being as women manage their multiple roles. This has been pivotal to our persistence during the pandemic.

\section{Employers of EdD Students}

\section{Create Safe Spaces for Honest Dialogue.}

Employers can build community and foster a sense of mattering by creating space for open dialogue between faculty, staff and administration (Schlossberg, 1989). This can be accomplished by scheduling virtual Town Hall meetings, or faculty and staff virtual coffee hours; this provides all employees the opportunity to share concerns, frustrations, and ideas. These gatherings help to limit feelings of isolation and can be a time for employees to celebrate success and stories of resilience. Employers can also work with their human resource department to develop and support affinity groups represented within doctoral programs, such as for women of color and other marginalized groups (Diggs et al., 2009). Research suggests affinity associations can provide faculty and scholarly practitioners of color a sense of belonging, mattering, and safety that is "essential for professional success" (Writer \& Watson, 2019, p. 38).

\section{Be Flexible and Open to Making Structural Changes.}

Employers can also support employees in doctoral programs by allowing them to create flexible work schedules. Studies suggest that a flexible work environment can improve employee retention (Maurer, 2019). For scholarly practitioners who are parents, balancing work, school, childcare, and in some cases eldercare, a flexible work schedule is specifically important for leaders who want to help their female employees persist in their program. One author noted that being able to adjust her work hours allowed her to be available for her children during the morning hours. At the same time, she was able to carve out time in the afternoon that allowed her to focus on EdD work. Another author expressed gratitude that the leadership team adjusted the college's classroom schedule so that classes were not held on Wednesday. Instead, Wednesday was used for chapel, faculty coffee, and other virtual gatherings.

\section{Acknowledge and Address the Challenges That Women Face.}

As institutions strive to support female scholars, it is important for them to acknowledge and address the obstacles that women face. This is especially important for scholars of color who face two of the most lethal preexisting conditions during a pandemic-racism and economic inequality (Gould \& Wilson, 2020). To support female 
scholars, supervisors can publicly speak about racism and gender bias with proficiency and an interesting in learning alongside fellow employees. Supervisors should also publicly condemn racism and work with human resources to implement consistent mandatory training for all employees around these issues. These trainings and conversations should provide employees of color the opportunity to share their experience, their pain, and concerns, while giving colleagues the chance to listen, to learn, and to become better allies (Creary, 2020).

\section{CONCLUSION}

Through this manuscript, we have critically reflected on ways in which the process of coping can be supported by the student and their respective role senders during periods of trauma and crisis. In doing so, we demonstrate the foundation of what being a scholarly practitioner is by taking on the responsibility of naming the barriers faced by female doctoral students while also framing recommendations for other students and stakeholders that are grounded in supportive literature (CPED, 2020).

The quest for a reprieve from the prolonged state of shared trauma is one that will continue until the pandemic ends, and for many, until well after it is over. For so many, searching for some semblance of normalcy during this period of extreme uncertainty was a daunting challenge, yet each individual was able to find ways to cope with these added stressors while also developing new ways to express a sense of hope for the future. Based on our reflections, the aforementioned recommendations are intended to be integrated into practice in order to benefit EdD students, their professional supervisors, as well as CPED-influenced EdD programs. It is essential that these programs learn from students' experiences and optimize this opportunity to reframe support structures. This support will prove to be essential as we continue to progress through a period when the accomplishments of the female doctorate are coming under fire with attempts made to diminish our progress and further suppress our voices. It will be powerful and dignified female leaders, such as Dr. Jill Biden, who will continue to pave the way for female doctorates to demand and ultimately receive the respect that being a female scholarly practitioner warrants. In following these footsteps and our provided recommendations, EdD programs can become more effective in continuing the quality education of scholarly practitioners who contribute to the leadership of higher education and its future.

\section{REFERENCES}

Babcock, L., Recalde, M. P., Vesterlund, L., \& Weingart, L. (2017). Gender differences in accepting and receiving requests for tasks with low promotability. American Economic Review, 107(3), 714-747.

CPED (2020). The CPED framework. The Carnegie Project on the Education Doctorate. https://www.cpedinitiative.org/the-

framework\#: :text=Scholarly\%20Practitioner\%3A\%20Scholarly\%20Pract itioners\%20blend,of\%20 equity\%20and\%20social\%20justice

Creary, S. (2020, July 8). How to be a better ally to your black colleagues. Harvard Business Review. https://hbr.org/2020/07/how-to-be-a-betterally-to-your-black-colleagues

Covey, S. (1989). The seven habits of highly effective people. Retrieved from https://www.franklincovey.com/the-7-habits/habit-2.html

Diggs, G. A., Garrison-Wade, D. F., Estrada, D., \& Galindo, R. (2009). Smiling faces and colored spaces: The experiences of faculty of color pursuing tenure in the academy. The Urban Review, 41(4), 312.
Gould, E., \& Wilson,V. (2020, June 1). Black workers face two of the most lethal preexisting conditions for coronavirus-Racism and economic inequality. Economic Policy Institute. Retrieved from https://www.epi.org/publication/black-workers-covid/

Guarino, C. M., \& Borden, V. M. H. (2017). Faculty service loads and gender: Are women taking care of the academic family? Research in Higher Education, 58(6), 672-694. https://doi.org/10.1007/s11162-017-9454-2

Hall, D. (1972). A model of coping with role conflict: The role behavior of college educated women. Administrative Science Quarterly, 17(4), 471 486. doi:10.2307/2393827.

Kahn, R. L., Wolfe, D., Quinn, R., Snoek, J., \& Rosenthal, R. (1964). Organizational stress: Studies in role conflict and ambiguity. Wiley.

Maurer, R. (2019, September 10). Flexible work critical to retention, survey finds. SHRM. https://www.shrm.org/resourcesandtools/hr-topics/talentacquisition/pages/flexible-work-critical-retention.aspx

McKinsey \& Company \& LEAN IN (2020). Women in the workplace 2020: The state of women in corporate America. https://wiwreport.s3.amazonaws.com/Women_in_the_Workplace_2020.pd

McMillan, D.W., \& Chavis, D.M. (1986). Sense of community: A definition and theory. American Journal of Community Psychology, 14(1), 6-23.

Mitchell, S. M., \& Hesli, V. L. (2013). Women don't ask? Women don't say no? Bargaining and service in the political science profession. Political Science \& Politics, 46(2), 355-369.

Schlossberg, N. (1989). Marginality and mattering: Key issues in building community. New Directions for Student Services, 48, 5-15.

Solly, M. (2020, June 4). 158 Resources to understand racism in America. https://www.smithsonianmag.com/history/158-resources-understandingsystemic-racism-america-180975029/

Walkington, L. (2017). How far have we really come? Black women faculty and graduate students' experiences in higher education. Humboldt Journal of Social Relations, 39, 51-65.

Writer, J. H., \& Watson, D. C. (2019). Recruitment and retention: An institutional imperative told through the storied lenses of faculty of color. Journal of the Professoriate, 10(2), 23-46. 